\title{
The enigma of consent
}

Peter Marks MB MRCP MSC LLB, Barrister at Law

Clin Med JRCPL 2001:1:118-20

Peter Marks

'Yes' is not simply the opposite of 'no'. It is a perspective of ethical, moral and cultural conclusions which changes in response to public awareness and medicolegal prompting. In 1976, in the case of Morgan ${ }^{1}$, 'no' was 'yes'. In November 1976 the Sexual Offences (Amendment) Act $1976^{2}$ made 'no' finally 'no'. This was not serendipity. In the case of Morgan, a raped woman was said to have consented because the rapists believed she was consenting. This caused a public outcry, and prompted the Sexual Offences (Amendment) Act 1976. The Act declared that, if at a trial for a rape offence, the jury has to consider whether a man believed that a woman was consenting to sexual intercourse, the presence or absence of reasonable grounds for such a belief is a matter to which the jury is to have regard, in conjunction with any other relevant matters in considering whether he so believed. The case of Morgan caused consternation. The expression of the case would be difficult to understand today.

\section{Medical procedures}

The case of Reibl $v$ Hughes $^{3}$ encapsulates much of the wisdom of medical consent. It deals with a neurosurgeon performing an operation to repair an artery in the plaintiff's neck to reduce the risk of stroke in later years. There was a serious risk of death or stroke in this type of operation. The plaintiff in fact did suffer a stroke and paralysis. The judgment found that the relationship between surgeon and patient gives rise to a duty of the surgeon to make disclosure to the patient of all material risks attending the surgery that is recommended. Even if a certain risk is a mere possibility that ordinarily need not be disclosed, yet if its occurrence carries serious consequences, as for example paralysis, or even death, it should be regarded as a material risk requiring disclosure. The risk attending the plaintiff's surgery or its immediate aftermath was the risk of a stroke, of paralysis and of death. This was a material risk. At the same time, the evidence made it clear that there was also a risk of a stroke and of resulting death if surgery for the removal of the occlusion was refused by the patient.

The court in Hopp $v$ Lepp $p^{4}$ also pointed out that even if a certain risk is a mere possibility which otherwise need not be disclosed, yet if its reoccurrence carries serious consequences, as for example, paralysis or even death, it should be regarded as a material risk requiring disclosure. The well-known statement of Cardozo J in Schloendorff $v$ Society of New York Hospital (1914) $)^{5}$ sets out that every human being of adult age and sound mind has a right to determine what shall be done with his or her own body.

Reibl $v$ Hughes and Hopp $v$ Lepp are Canadian cases. However, their influence entered English law in the case of Sidaway $v$ Board of Governors of Bethlem Royal Hospital ${ }^{6}$. This encapsulates the legal wisdom with regard to the duty to warn. In this case it was held that the question whether an omission to warn a patient of inherent risks of proposed treatment constituted a breach of a doctor's care towards his patient was to be determined by an application of the Bolam $^{7}$ test; save that although the degree of disclosure required for a particular patient was an issue to be judged primarily on the basis of medical evidence, there might be circumstances where the proposed treatment involved a substantial risk of grave consequences in which a judge could conclude that, notwithstanding any practice to the contrary accepted as proper by a responsible body of medical opinion, a patient's right to decide whether to consent to the treatment was so obvious that no prudent medical man could fail to warn of the risk save in emergency or some other sound clinical reason for non disclosure.

Law, however, rarely arises by chance or in isolation. It is multifocal and eclectic. The Canadian and American cases (Reibl $v$ Hughes, Hopp $v$ Lepp, Schloendorff $v$ New York Hospital) expressed a change in public mood and judicial thinking. This was not merely local or national but international. This process has continued.

Informed consent is the agreement that makes it possible to perform invasive procedures. It follows therefore that the doctor may only perform the invasive procedure for which informed consent was given. In the case of Mitchell ${ }^{8}$, a consultant anaesthetist gave a suppository for postoperative pain to a woman after she had had four wisdom teeth extracted. He did not seek consent preoperatively for use of the suppository. He was found guilty of serious professional misconduct before the General Medical Council and admonished.

Many cases have followed on from this decision. The position in other European countries has 
mirrored this transition. The legal position with regard to informed consent in Denmark offers the principle that the plaintiff's right to self-determination culminating in his or her consent to medical treatment is a basic civil right. A prerequisite for meaningful consent is naturally that the patient has received sufficient information from the physician to permit him or her to make a rational choice. Two misconceptions about informed consent concern the difference between the legal and ethical justification. Legally informed consent is a risk management tool that functions essentially as a release from liability. If the patient is informed of all expected or potential complications of a treatment, he or she cannot sue should those complications occur. The ethical doctrine of informed consent is derived from respect for the patient's autonomy as well as the patient's vulnerability. The role of the doctor is not to minimise liability but to help the patient make the best decision. These two goals are not inconsequential but they can lead to different decisions about what information needs to be shared with patients. Parliamentary debates in Denmark have revealed that the main political purpose of informed consent legislation is to ensure the right of patients to self-determination'.

The revision of the Medical Act 1992 in Denmark expressly mentioned for the first time that physicians have an obligation to inform their patients ${ }^{10}$. This in fact is Law 426 of 19 August 1987, the first revision of which came into force on 1 October 1992. In addition, the disciplinary board has in two circulars in $1982^{11}$ and $1992^{12}$ clarified the principles regarding information and consent.

An investigation of all patient complaints received by the disciplinary board during the period 1980 to 1986 led to the conclusion that complaints regarding information and consent comprised $6.6 \%$ of the complaints received ${ }^{13}$. Moreover, this type of complaint was the one most often upheld by the disciplinary board. The disciplinary board, however, handed down lenient sanctions, such as cautions. Furthermore, if the complaint comprised lack of information only, the conduct was not deemed to have contravened the Medical Act. The courts in Denmark have very rarely had to pass judgment regarding questions of information and consent. Indeed, within ten years there were only three published verdicts.

\section{Experimental procedures}

The criminal and civil codes in Germany prohibit the violation of the person, be it in the way of assault and battery, by negligence or in the form of abrogation of the right to privacy. Under these terms cases of coercive or negligent experimentation on humans can be brought before the criminal and civil courts. Indeed, in 1956 of the Federal Supreme Court decided a case of medical experimentation solely on the basis of private law. Following the established rules of liability the court distinguished between the therapeutic and purely scientific research, and stressed the need for informed consent and awarded compensation ${ }^{14}$.

The physician and the institution conducting the medical experimentation are liable for negligence. On the one hand, the federal constitution guarantees the freedom of research and science, but on the other hand, medical research should not harm the patient or proband. If the research is conducted negligently ${ }^{15}$ or is undertaken without informed consent the doctor and the institution are liable for damages and for pain and suffering. There is as yet no strict liability in German law as far as experimentation is concerned ${ }^{16}$.

Liability for negligence (Verkehrspflichtverletzung) in the German law of torts can be very strict. Therefore, it is safe to assume that a German court will set very strict standards for medical experimentation. The usual approach with liability for negligence, ie asking whether the risk is currently tolerable for society, does not apply to experimentation. Therefore, as in the recent English case, The Plaintiffs $v$ UK Medical Research Council ${ }^{17}$, Mr Justice Moreland was right in holding the defendants liable, because they did not conduct clinical studies when the first suspicions of severe side effects were raised. The case concerned the giving of human growth hormone extracted from cadavers to treat pituitary deficiency in young patients. The result of the treatment was that nineteen children suffered from Creutzfeldt-Jakob disease, and sixteen died. The setting of high standards for medical care in cases of medical experimentation does not quite equal a strict liability but comes near to it.

If a proband is obliged to undergo medical experimentation by law, he is entitled to compensation if anything happens to him. The German Federal Supreme Court in 1956 decided the case of the German soldier who had been treated at Heidelberg University during the war because of an injury that had caused an aneurysm of the femoral artery. Arteriography had been performed more than once using Thorotrast (a contrast medium used in radiography). Despite an occasional warning in the late 1930s that Thorotrast might have long-range severe side effects, the Greek chief of service decided to try it out on many soldiers to dispel possible doubts associated with Thorotrast. The soldier suffered cirrhosis of the liver. He sued Heidelberg University and won the case. The court concluded that the arteriographies had been mostly for research and the health of the soldier was in no way improved by doing more than one arteriograph. Since the soldier had not been adequately informed, and had not given his consent to the experimentation procedure, but on the other hand had been under military orders and could not very well have refused, he was awarded a substantial sum, not as damages but as compensation for having sacrificed his personal rights by acting as an experimental subject while under the command of the army ${ }^{18}$.

The German law encompasses safeguards for potential patients, as does French law. The French law of 20 December 1988 (which requires physicians to inform patients about the effects of a treatment or drug, and obtain informed consent for a specific treatment) begins to change the perceptions of the doctor-patient relationship ${ }^{19}$. Clearly, the archetypal paternal relationship is giving way to a sharing of the decision-making process. There clearly is a potential for alienation of patients from physicians and the effects of this alienation on treatment effectiveness must be considered. 


\section{Competence}

Competent patients may reject proposed medical care. This right is denied to incompetent patients and others may make their decisions. The ultimate assessment of competence is a legal concept. Whilst it can only be formally determined through legal proceedings, the law presumes patients' competence, and unless serious questions arise about their competence, then the physicians should accept their wishes. The procedures and requisite standards for assessing competence to make decisions varies with regard to jurisdiction. However, the majority would agree with the legal standard falling within the four categories of understanding relevant information, appreciating the situation and its consequences and manipulating information rationally ${ }^{20}$.

\section{Presumed consent}

The doctrine of informed consent is not simply a hindrance to medical practice. Its value and use can be moulded to suit the needs of society and in this respect the doctrine of presumed consent is a mechanism by which a desirable outcome can be achieved. Presumptions of fact are simply logical inferences of the existence of one fact from the proved existence of others. They are the inferences of presumption which render circumstantial evidence admissible. Thus a presumption is the way in which society encapsulates its wisdom, morality and ethics. It essentially says that this particular association need not be proved on each occasion, since it is taken to be so. It is simple and certain.

\section{Organ transplantation}

The NHS depends entirely on the availability of donor organs. Since 1972, over 30,000 organs have been donated to the NHS. However, demand increases whilst supply does not. Campaigns such as 'Carry a Card' and the national computerised register of donors increases awareness but it is still not sufficient. The wishes of many patients are simply not known. This does not mean that they have refused or that they would have refused but merely that they have not indicated their wishes. The doctrine of presumed consent would satisfy this need. Instead of opting in, one would opt out. Consent would be presumed unless the patient had specifically chosen to opt out.

\section{The future}

Medicine remains a balance between the paternalistic and the modern questioning against the background of an increasingly empowered public. The tension between these two opposite philosophies accounts for the increased questioning of medical decisions and treatments. The growth of the medical negligence industry and the deterioration of the doctor-patient relationship are consequences of this failure to achieve consensus. Since that to which a person consents cannot be deemed an injury, the doctrine of informed consent removes the fear of failure of expectation from the decision-making process. The progression of this doctrine has been different in different jurisdictions and the momentum of this process will have unintended consequences. However, by carefully evaluating change and consequence, it will be possible to suit form to function to the ultimate benefit of all.

\section{References}

1 DPP v Morgan (1976) AC 182, 61 Cr App Rep 136 HL.

2 Sexual Offences (Amendment) Act 1976.

3 Reibl v Hughes (1978) 89 DLR (3d) 112, (1981) 114 DLR (3d).

4 Hopp v Lepp (1980) 2 SCR 192 208, 112 DLR (3d) 6785.

5 Schloendorff $v$ Society of New York Hospital (1914) 211 NY 125.

6 Sidaway v Board of Governors of Bethlem Royal Hospital (1985) 1 All ER 643, (1985) AC 871, (1985) 2 WLR 480 HL.

7 Bolam v Friern Hospital Management Committee (1957) 2 ALL ER 118.

8 Hoyte P. Basic principles of consent: points for consideration. Hospital Medicine 1998;59:236.

9 Segest E. The legal position with regard to informed consent in Denmark. Med Law 1985;14:245-54.

10 Medical Act in Denmark (Law 426 of 19 August 1987) the latest revision of which came into force on 1 October 1992.

11 National Board of Health Medical Practitioners' Duty and the Patients' Rights, circular regarding information and consent of 21 October 1982.

12 National Board of Health Medical Practitioners' Duty and the Patients' Rights, circular regarding information and consent of 22 September 1992.

13 Segest E, Petersen F. Evaluation of the physicians' obligations to provide information in Denmark. Med Law 1988;7:141-9.

14 Entscheidungen des Bundesgerichtshof in Zivilsachen. Reports of the Federal Supreme Court in Civil Cases 1951.20.61.

15 Deutsch E. The protection of the person in medical research in Germany. Med Law 1999;18:77-92.

16 Jung A. Die Zulässigkeit biomedizinischer Versuche am Menschen. Heymann, 1996.

17 The Plaintiffs v. UK Medical Research Council and Secretary of State for Health. Bull Med Ethics 1996;November:16.

18 Entscheidungen des Bundesgerichtshof in Zivilsachen. Reports of the Federal Supreme Court in Civil Cases 1951.20.62.

19 Henry A, Cohen G, Richie C. Les essais therapeutiques. La relation 'médecin malade' a travers la loi du 20 décembre 1988. Psychologie Médicale 1990;22:516-18.

20 Applebaum PC, Grisso T. Assessing patient's capacities to consent to treatment. N Engl J Med 1988;319:1635.

Address for correspondence:

Dr Peter Marks, 1 Maxted Road, London SE15 4LL. 